\title{
Sustainable Approach to Produce Polyurethane Composite Foams with Natural Materials
}

\author{
Hüseyin Avc1*, Anıl Umut Özdemir \\ Metallurgical and Materials Engineering, Eskisehir Osmangazi University, Eskisehir, 26040, \\ Turkey, +90222 239 3750-3688, \\ havciesogu@gmail.com \\ *Corresponding Author
}

Received: 21 February 2017

Accepted: 7 November 2017

DOI: $10.18466 /$ cbayarfbe. 293113

\begin{abstract}
Due to the rapid increase in population growth, energy and synthetic material consumption, the materials which reduce energy consumption like isolation structures have been gaining an importance after results of many innovative researches. So far, the most part of energy reducing materials have been produced by synthetic chemicals and therefore have a detrimental effect on the natural world and living organisms. Rigid polyurethane foam (PUF) is mainly manufactured by synthetic raw materials and widely used as an isolation material for different applications. Here, we present a novel composite PUFs contain different amount of natural materials as fiberglass, straw and basalt fibers between $0.5 \%$ and $2 \%$ by weight. Thermal conductivity is varied from 0.02109 to $0.02260 \mathrm{~W} /(\mathrm{m} . \mathrm{K})$ by using $1 \%$ and $2 \%$ for fiberglass and straw, respectively. Furthermore, there is no significant change for the compression strengths of the resulted composites when compare with virgin PUF except $2 \%$ fiberglass which demonstrates about $70 \mathrm{kPa}$ performance. We strongly believe that lowering synthetic raw materials content for PUF by incorporating natural materials will have a proportionately less harmful impact on the ecology and natural sustainability while keep similar thermal and physical properties to those of the current $100 \%$ synthetic PUFs.
\end{abstract}

Keywords: Composites, eco-friendly, low thermal conductivity, natural materials, polyurethane foam.

\section{Introduction}

Since polyurethane (PUR) was discovered by Otto Bayer and his coworkers in 1937, it became one of the most versatile polymers with a broad range of applications because of their relatively easy processing and excellent mechanical properties $[1,2]$. Flexible and rigid polyurethane foams are two major categories even if there are some hybrid types of semi-rigid and semi-flexible foams [3]. Applications of many uses of PUFs depend of its type including the range from building insulation, furniture for bedding and seating, footwear, automotive, transportation to refrigerators in almost any variety of shapes and firmness [4].

Due to the wide range of operating conditions and desired properties and performance of PUFs, currently, the main raw materials of polyol and isocyanate are derived from petroleum-based precursors. In addition, the materials which are used for swelling and surface activator are important to obtain specific properties and potential application in several technical fields [5]. At the same time, increased consumer awareness of environments and living organisms, many recent works have focused alternative, eco-friendly and bio-based raw materials to synthesize PUFs. In addition to the nature of chemical components, there are many factors that affect the polyurethane's mechanic and thermal properties such as cell size, solid/gas ratio, ratio of admixture materials, curing period, production type and air permeability. Many scientific researches have been conducted on the purpose of non-petroleum derived polyols to manufacture PUFs such as lignin [6], soy [7], starch and potato $[8,9]$, palm [10] are some valuable approaches. Kucukakinci et al. [11] admixed natural fibers and PUR during PUFs production with the aim of investigation to the thermochemistry and mechanical properties. They used cotton fibers and bamboo as natural fibers with a specific proportion. At the end, well enough thermal property was obtained in PUF wich includes 4\% cotton. Beltran and Boyaca [12] produced rigid PUFs as using the soybean oil derived polyol at the ratio of between $20-30 \%$. Then, they evaluated the soybean oil based PUFs thermal and mechanical properties.

In addition, Silva et al. [13] produced cellulose fiber reinforced rigid PUFs and analyzed the effects of cellulose fibers content. Kim et al. [14] have manufactured fiberglass 
reinforced PUR and they examined the effects of fiberglass on PUFs mechanical, thermal properties and cell morphology as well. It has found that the amount of fiberglass is a critical to balance between mechanical strength and thermal conductivity. On the other hand, an interesting study has been performed by Pielichowski et al. [15] to analyze the influence of additives of carbonate and phosphate-stabilized materials blown with pentane on thermal degradation. The results revealed that improved thermal decomposition properties can be obtained with the formation of the barrier between the transfer of flame/heat and the decomposition zone. Seo and Hyun et al. [16] obtained PUR by using deionized water as an embossment agent. They investigated how to change the PUFs mechanical, morphological and thermal properties by using deionized water. As a result, adding deionized water caused to decrease PUFs mechanical properties. However, according to thermal analyses, glass transition temperature increased from 49.5 to $80.8^{\circ} \mathrm{C}$ and at the same time the cell size raised from 115 $\mu \mathrm{m} 258 \mu \mathrm{m}$. Moreover, Yang et al. [17] used two different types of basalt fibers for PUR surface treatment and found a negligible improvement in mechanical properties. Ragauskas et al. [18] produced cellulose nanowhiskers and used as reinforcing agent for PUR. It is realized that the nanosized cellulose nanowhiskers have better properties like recycling and biodegradability in the nature, degradation easily in water and endogenous high resistance in almost all other nano admixture materials using traditionally. On the contrary, it is important to mention that cellulose nanowhisker's dispersion in the mixture is very difficult because of their hydrophilic property. However, due to no any negative effect on PUFs and expanding process, it has a potential to be used in the industry and the market in the near future after solving the problem related with dispersion.

However, many important challenges still remain aforementioned studies to satisfy for practical applications in the terms of properties and performance of PUFs when compared with PUFs based on petroleum-dependent feedstocks. Targeted aim in our study was to improve or at least keep the similar performance of thermal and mechanical properties of PUFs by adding natural materials via determined specific ratios as a partially replacement to decrease the harmful effects of synthetic raw materials to the nature. After an extensive literature review, we have decided to use fiberglass, straw and basalt fibers due to their lower coefficient of thermal conduction, relatively low-cost, ease of manufacture and their versatility. Furthermore, our method was proven to be applicable for industrial manufacturing facilities. Finally, the optimal combination has been determined based on the resulted PUFs composites.

\section{Materials and Methods}

\subsection{Materials}

A commercially used polyol compounds with $450 \mathrm{mg}$
$\mathrm{KOH} / \mathrm{g}$, equivalent weight of 124.65 and 4,4'-diphenylmethane diisocyanate with having $31 \%$ of NCO groups and $200 \mathrm{mPa}$.s viscosity were used to produce the rigid foams for thermal insulation property. In addition, the blowing agents of isopentane or cyclopentane was also utilized. The mix ratio of the polyol and the isocyanate with other materials is shown in Table 1 .

Originally, basalt fiber is obtained by melting process of the basalt rocks via finely fragmented process. There is no any extra additive in basalt fiber during the production with the advantages of final price [17]. Furthermore, their impact resistances are high against the chemicals. Coefficient of thermal conduction is approximately $0.031-0.038 \mathrm{~W} /(\mathrm{m} . \mathrm{K})$ [19]. In general, basalt fiber has higher tensile strength than the fiberglass with demonstrating better breaking/fracture strength than the carbon fiber [20]. In our study, 4 and $7 \mathrm{~cm}$ sized-basalt fibers were obtained from Tila Kompozit Temsilcilik Ic ve Dis Tic. Ltd. Sti. İstanbul/Turkey and used as it is arrived (Figure 1).

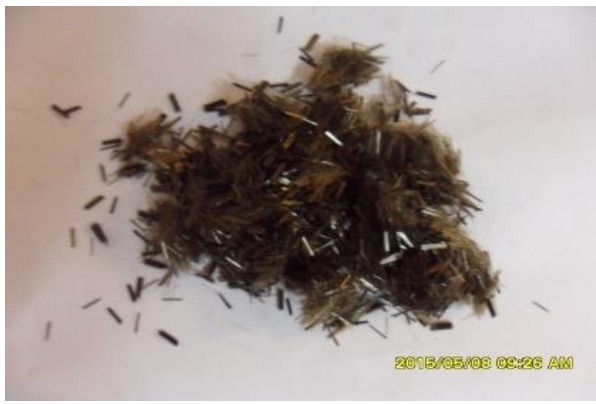

Figure 1. An image of basalt fiber.

In our research, we also have used a very small size of fiberglass as shown in Figure 2 with the coefficient of thermal conductivity which is about $0.04 \mathrm{~W} /(\mathrm{m} . \mathrm{K})$ [20]. It is well known as one of the most common heat insulation materials.

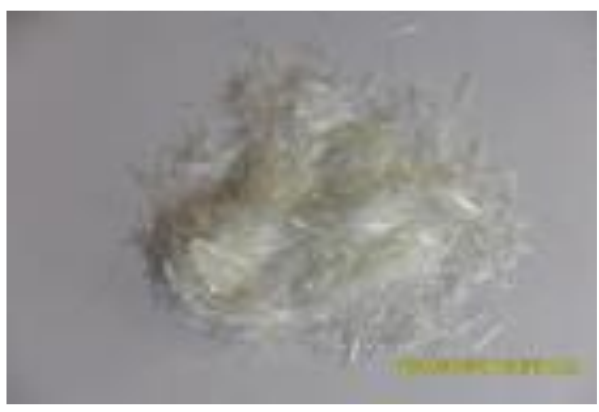

Figure 2. An image of fiberglass.

Final natural material is a straw which was supplied from Karagozler village/Eskisehir/Turkey which has individual fiber size of 5 to $8 \mathrm{~mm}$ (Figure 3). In general, the coefficient of thermal conductivity is calculated after obtaining the form of the sheet for the insulation of outdoors. However, it is intensively discussed in the literature because of a huge 
variety of their nature, porous structure, orientation and density. Therefore, representative values are frequently between $0.04-0.08 \mathrm{~W} /(\mathrm{m} \mathrm{K})$ [21].

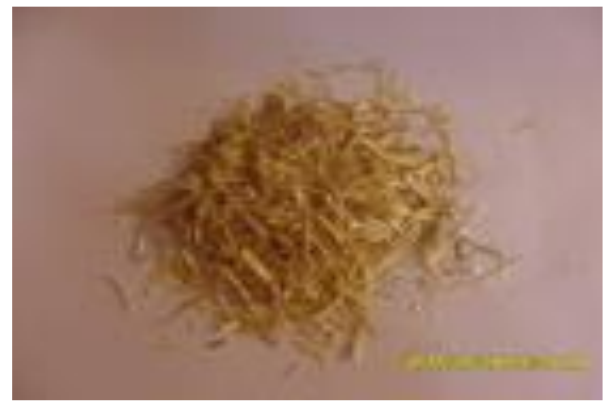

Figure 3. An image of straw used for the experiment.

\subsection{Production of Composite PUFs}

The polyol and pentane with additives were mixed by the hand mixing process till obtaining homogeneous composite structures (Table 1). At the beginning, in designing composite materials, we aimed to combine the maximum amount of natural materials to the composite structures without losing desired properties. However, during the experimental study, when we increased the natural content more than $2 \%$ by weight, the foam structure was not fully achieved. Therefore $2 \%$ and lower constituent materials were chosen. After the optimization process for homogeneous mixing, the blending time was taken about 4 seconds and then stopped because of starting of the foaming process. The

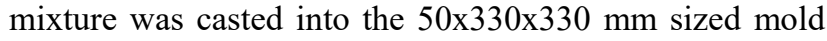
and the surface was covered during the all process steps. At the beginning of the production, the mold was oiled for easily lifting of PUFs. The total time for the process was about 5 minutes and PUFs were separated from the mold by removing the edges with the help of a sharp object.

Table 1. Chemical composition of virgin and natural reinforced (NRF) composite of PUFs.

\begin{tabular}{|c|c|c|c|}
\hline $\begin{array}{c}\text { Sample } \\
\text { (PUFs) }\end{array}$ & Polyol (\%) & $\begin{array}{c}\text { Isocyanate } \\
\text { (gr/unit) }\end{array}$ & $\begin{array}{c}\text { Pentane } \\
\text { (gr/unit) }\end{array}$ \\
\hline Virgin & 100 & 150 & 13 \\
\hline $0.5 \%-N R F$ & 99.5 & 149.25 & 12.935 \\
\hline $1 \%$-NRF & 99 & 148.5 & 12.87 \\
\hline $2 \%-N R F$ & 98 & 147 & 12.74 \\
\hline
\end{tabular}

\subsection{Coefficient of Thermal Conductivity}

Coefficient of thermal conductivity was measured by the hot plate method as using ASTM C177 standard [22]. In this method, PUFs samples were placed between two different temperatures of the plates in which one plate was 38 ${ }^{\circ} \mathrm{C}$ while other one was set to $10^{\circ} \mathrm{C}$. The purpose was to observe the heat transfer of the PUR in the environment that includes temperature gradients. The sample size was adjusted to $50 \times 300 \times 300 \mathrm{~mm}$. The required time for the test was approximately 30 minutes.

\subsection{Mechanical Properties}

Compressive mechanical properties were measured using a Zwick/ Roell Z010 test device under the compression mode with $3 \mathrm{~mm} / \mathrm{min}$ crosshead speed. The specimens were cut in to cube shape according to ASTM D 1621 test standard [23] with the following dimensions; $30 \mathrm{~mm}$ (length), 30 $\mathrm{mm}$ (width) and $30 \mathrm{~mm}$ (thickness).

\subsection{Cell Size Analyses}

An Olympus SZ-PT stereo microscope was used to analyze the average cell size of the foams after painting by lightly ink. The cell shape and sizes as in Figure 4 was investigated by inspecting visually using at least 35 cells on $\mathrm{x}$ - and $\mathrm{y}$ axis.

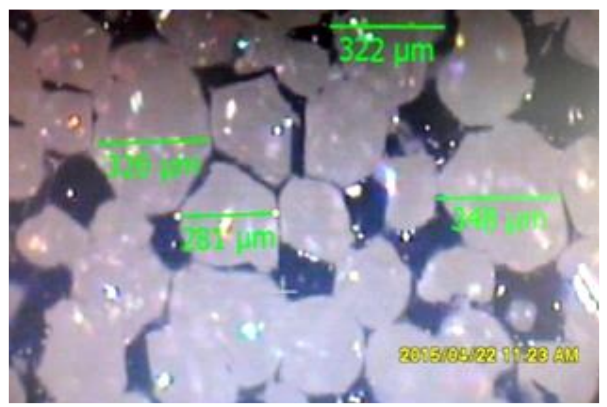

Figure 4. An image of the stereo microscope (left) and the cell structures in PUFs (right).

\section{Results and Discussion \\ 3.1 Morphology of rigid PUFs}

The density, closed cell content and cell size of the resulting foams were evaluated to assess the effect of the content of these adding materials on the performance of the PUFs. In general, the foam density did not significantly vary with the addition 0.5 and $1 \%$ reinforced materials and it was around $31-32 \mathrm{~kg} / \mathrm{cm}^{3}$. Only the foam with $2 \%$ reinforced materials based showed a noticeable change from 31 to $39 \mathrm{~kg} / \mathrm{cm}^{3}$. In addition, the highest closed cell content was found around $91 \%$ for the composite consists of $0.5 \%$ fiberglass, and then followed by basalt and straw reinforced foams of 85 and $84 \%$, respectively. Except the straw fiber reinforced composite, there is a trend in which closed cell content decreased while the content of the reinforced materials increased.

Different parameters can influence the cell size of the foam (Figure 5). The nucleation with the coalescence of cells are two important factors from a practical perspective during the production process for the final foam. In our study, by the increasing the additive amount in the foam, the obtaining of homogeneous distribution became difficult and the cell structure begins to deteriorate. It can be realized in Figure 5 that $0.5 \%$ basalt fiber reinforced PUFs morphology 
showed a homogeneous distribution. When the content was increased to $1 \%$, the average cell size increased from 223 $\mu \mathrm{m}$ to $231 \mu \mathrm{m}$. But, the homogeneity in cell sizes significantly decreased when the basalt fiber content was adjusted to $2 \%$. Likewise, the cell morphology of $0.5 \%$ straw reinforced PUFs demonstrated a homogeneous distribution and there was a disappearance of homogeneity while we increased the straw content gradually. On the other hand, the effect of $0.5 \%$ fiberglass content on cell distribution was similar and homogeneous structure was observed like the other reinforced materials. When increasing the fiberglass content from $0.5 \%$ to $1 \%$, unexpectedly the cell size decreased from $191 \mu \mathrm{m}$ to $180 \mu \mathrm{m}$ and the homogeneous distribution started to lose. In this case, when the fiberglass ratio was increased to $2 \%$, the fiberglass could not homogeneously distribute in the mixture and it started to wind around the mixer.

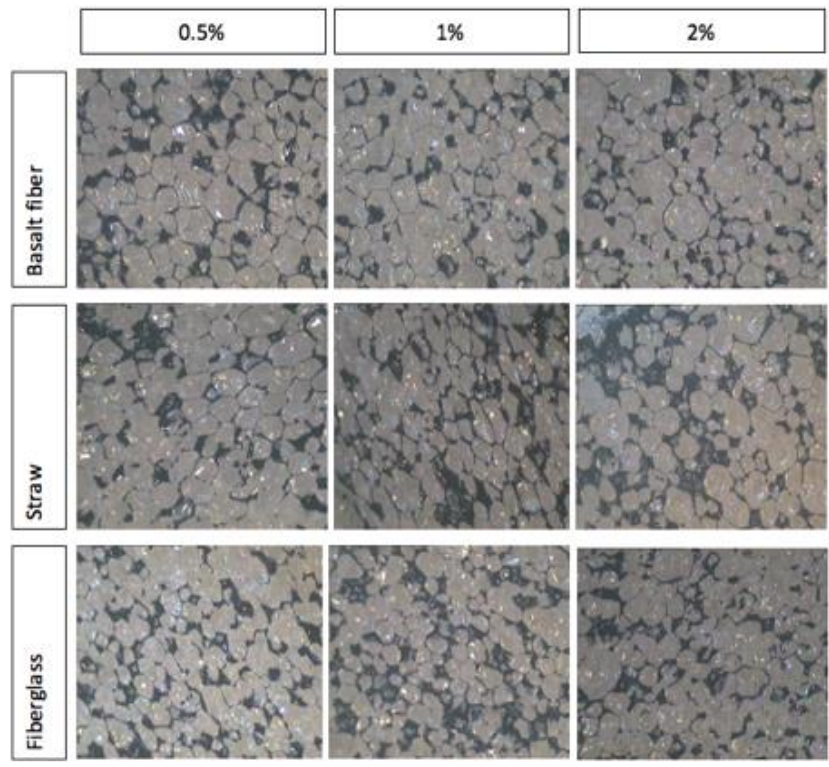

Figure 5. Microstructures of composite PUFs samples.

\subsection{Mechanical Properties}

Foam density and foam structure are two important parameters to determine the compressive properties [24-25]. As is seen in Figure 6, the compression strengths of the obtained composites of PUFs exhibited different performance based on the additive percentage although there is no significant change for the performance between the all foams including virgin PUF except $2 \%$ fiberglass reinforced composite. In the case for basalt reinforced PUFs, the foam density and closed cell content demonstrated a similar value and there was no remarkable difference for $0.5,1$ and $2 \%$, hence the composite PUFs maintain its mechanical performance. The increase in cell size with adding the reinforced material from 0.5 to $1 \%$ provided to observe a higher compressive strength which presumably related uniform and higher density with less buckling during the compression test [26]. On the other hand, $1 \%$ straw reinforced composite
PUFs demonstrated lower performance when compared with composites include 0.5 and $2 \%$ straw content. In this case, even if the density of 0.5 and $1 \%$ reinforced foams are similar, the low closed cell content for the $1 \%$ foams caused to decrease in the compressive strength which is also clearly indicated by the literature [27].

As expected, 2\% fiberglass reinforced composite PUFs demonstrated the lowest compression strength. Probably, the most important reason for the total destruction was that the fiberglass started to entangle around the mixer during the mixing process which prevented the formation of the full uniform foaming during the composite production.

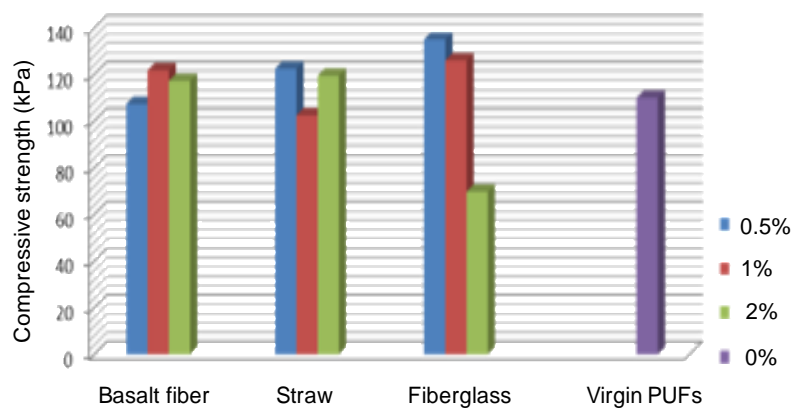

Figure 6. Natural fibers and materials reinforced composite PUFs.

\subsection{Thermal Conductivity}

The thermal conductivity of an insulating material strongly depends on the solid polymers and materials. Table 2 shows resulted coefficient thermal conductivity values of different composite of PUFs. It can be easily realized that the lowest performance was obtained from straw reinforced PUFs with around $0.022 \mathrm{~W} /(\mathrm{m} . \mathrm{K})$. From this, it can be concluded the thermal conductivity of the reinforced material seems to be the highest priority in comparison to the other parameters. Therefore, for the foams, which are manufactured by using basalt, straw and fiberglass, are mainly governed by their coefficient of thermal conduction. Since the coefficient of thermal conductivity of basalt fiber and fiberglass are close to each other, their composite structures have similar thermal conductivity as expected. In other respects, thermal conductivity performance decreased with increasing the value from 0.02201 to $0.02260 \mathrm{~W} /(\mathrm{m} . \mathrm{K})$ while we increased the straw ratio in the PUFs. For basalt fiber, similar coefficient of thermal conductivity values was obtained for 3 different additive ratios. 1\% fiberglass reinforced polyurethane foam has the lowest coefficient of thermal conductivity in which $0.02109 \mathrm{~W} /(\mathrm{m} . \mathrm{K})$ value was obtained.

On the other hand, there was no any significant difference between natural fibers-reinforced foams and virgin PUR foam in the terms of the coefficient of thermal conductivity. Also, in addition to the structural compliance and development, presumably higher level of homogeneous mixing of fiberglass with polyurethane foam plays an important role 
for obtaining the lowest thermal conductivity while closed cell content and density stands for the rest.

Table 2. Coefficient of thermal conductivity values of virgin PUFs and NRF composite foams (W/(m.K)).

\begin{tabular}{|c|c|c|c|c|}
\hline \multirow{2}{*}{$\begin{array}{c}\text { Adding } \\
\text { amount } \\
(\%)\end{array}$} & $\begin{array}{c}|c| \\
\text { Basalt } \\
\text { fiber }\end{array}$ & Straw & $\begin{array}{c}\text { Fiber- } \\
\text { glass }\end{array}$ & $\begin{array}{c}\text { PUrgin } \\
\text { PUF }\end{array}$ \\
\hline 0.5 & 0.02193 & 0.02201 & 0.02138 & - \\
\hline 1 & 0.02172 & 0.02252 & 0.02109 & - \\
\hline 2 & 0.02190 & 0.02260 & 0.02176 & - \\
\hline Virgin & - & - & - & 0.02184 \\
\hline
\end{tabular}

\section{Conclusion}

Progress towards environmentally responsible processing becomes more globalized and has its great impact on various sectors including health, constructions, industrial and many others [28-31].

This research presents an investigation to incorporate natural materials to PUFs in order to decrease the harmful effects of the synthetics. Since the properties and performance of traditional PUFs based on fossil resources demonstrate higher advancement than renewable biomass resources, it is encouraging to partially replace the petrochemicals with the biomass resources.

The investigations have shown that there is no any significant difference in physical properties among the virgin PUR and the resulted composite foams including the natural additives. In addition to that during the PUFs production, it was difficult to obtain homogeneous mixture and desired cell morphology which were probably deteriorate the structure when we increased the proportion of the natural fibers. This alteration negatively affected the mechanical properties and the coefficient of thermal conductivity. Thus, the optimum production parameters and well-structured PUFs were obtained after many trials. The coefficients of thermal conductivity of almost all samples showed the similar value with the reference of PUFs. The best result which we achieved for thermal conductivity is 0.02109 $\mathrm{W} /(\mathrm{m} . \mathrm{K})$ by using $1 \%$ fiberglass. Based on our observations, better thermal conductivity and mechanical properties can be obtained with using smaller size like nano-based additives via injection method.

On the other hand, it is estimated that 96 million tons of PUFs was produced in 2015. By using this simple, cost efficient and practicable method, an approximately 100 thousand tons of synthetic chemicals can be saved by only adding $1 \%$ natural fibers to the PUFs. It is considered this result will generate an important positive effect on living creatures, environment and economy as well.

\section{Acknowledgment}

The authors are thankful to Arcelik Plant in Eskisehir, Turkey. The authors also gratefully acknowledge TEMAG Laboratories, ITU Faculty of Textile Technologies and Design and Tila Kompozit Temsilcilik for providing fiberglass and basalt fibers, respectively.

\section{Referanslar}

1. Sharmin, E., Zafar, F. Polyurethane: An Introduction; INTECH Open Access Publisher, 2012; 3 pp.

2. Oertel, G. Polyurethane Handbook, 2nd ed.; Hanser: New York, 1994.

3. Ashida, K. Polyurethane and Related Foams Chemistry and Technology; Florida: Taylor \& Francis Group, 2007; 8 pp.

4. Szycher, M. Handbook of Polyurethanes; Woburn, MA: CardioTech International Inc., 1999; 48 pp.

5. Demharter, A. Polyurethane Rigid Foam, a Proven Thermal Insulating Material for Applications Between $+130^{\circ} \mathrm{C}$ and $-196^{\circ} \mathrm{C}$. Cryogenics. 1998; 38(1), 113-117.

6. Jin, Y.; Ruan, X.; Cheng, X.; Lü, Q. Liquefaction of Lignin by Polyethylene Glycol and Glycerol. Bioresource Technology, 2011; 102, 3581-3583.

7. Gu, R.; Sain, M.M. Effects of Wood Fiber and Microclay on the Performance of Soy Based Polyurethane Foams. Journal of Polymers Environmenty, 2013; 21(1), 30-38.

8. Kwon, O.; Yang, S.; Kim, D.; Park, J. Characterization of Polyurethane Foam Prepared by Using Starch as Polyol. Journal of Applied Polymer Science, 2006; 103, 1544-1553.

9. David, J.; Vojtová, L.; Bednarík, K.; Kucerik, J.; Vávrová, M.; Jancár, J. Development of Novel Environmental Friendly Polyurethane Foams. Environmental Chemistry Letters, 2009; 8(4), 381-385.

10. Tanaka, R.; Hirose, S.; Hatakeyama, H. Preparation and Characterization of Polyurethane Foams Using a Palm Oil-Based Polyol. Bioresource Technology 2008; 99, 3810-3816.

11. Büyükakinci, B.Y.; Sökmen, N.; Kucuk, H. Thermal Conductivity and Acoustic Properties of Natural Fiber Mixed Polyurethane Composites. Research Journal of Textile and Apparel, 2011; 21(2), 124-132.

12. Beltrán, A. A.; Boyacá, L. A. Production of Rigid Polyurethane Foams from Soy-Based Polyols. Latin American Applied Research, 2011; 41(1), 75-80.

13. Silva, M.C.; Takahashi, J.A.; Chaussy, D.; Belgacem, M.N.; Silva, G.G. Composites of Rigid Polyurethane Foam and Cellulose Fiber Residue. Journal of Applied Polymer Science, 2010; 117(6), 36653672 .

14. Kim, S.H.; Park, H.C.; Jeong, H.M.; Kim, B.K. Glass Fiber Reinforced Rigid Polyurethane Foams. Journal of Materials Research, 2010; 45(10), 2675-2680.

15. Pielichowski, K.; Kulesza, K.; Pearce, E.M. Thermal Degradation Studies on Rigid Polyurethane Foams Blown with Pentane. Journal of Applied Polymer Science, 2003; 88(9), 2319-2330. 
16. Seo, W.J.; Jung, H.C.; Hyun, J.C.; Kim, W.N.; Lee, Y.B.; Choe, K.H.; Kim, S.B. Mechanical, Morphological, And Thermal Properties of Rigid Polyurethane Foams Blown by Distilled Water. Journal of Applied Polymer Science, 90(1), 12-21.

17. Ting; Y.; Zhenjin, C.; Jiahui, Y.; Yuqiu, Y.; Hiroyuki, H. Polyurethane Surface Treatment on Two Kinds of Basalt Fiber Composite and Mechanical Properties Comparison. Online available at (February 20, 2017): tive.com/SPEA_CD/SPEA2014/pdf/RF/RF6.pdf

18. Li, Y.; Arthur, J. R. Cellulose Nano Whiskers as a Reinforcing Filler in Polyurethanes. Algae. 2011; 75(80), 10-15.

19. Bolshakova, N. V.; Kostenok, O. M. Thermal Conductivity of Basalt Fiber Materials. Refractories. 1995; 36(10), 331-332.

20. Singha K. A Short Review on Basalt Fiber. International Journal of Textile Science, 2012; 1(4), 19-28.

21. Costes, J.P.; Evrard, A.; Biot, B.; Keutgen, G.; Daras, A., Dubois, S.; Lebeau, F.; Courard, L. Thermal Conductivity of Straw Bales: Full Size Measurements Considering the Direction of the Heat Flow. Buildings, 2017; 7(11), 1-15.

22. ASTM C177 - 13. Standard Test Method for Steady-State Heat Flux Measurements and Thermal Transmission Properties by Means of the Guarded-Hot-Plate Apparatus. Online available at (February 20, 2017): https://www.astm.org/Standards/C177.htm

23. ASTM D1621 - 16. Standard Test Method for Compressive Properties of Rigid Cellular Plastics. Online available at (February 20, 2017): http://www.astm.org/Standards/D1621

24. Gama, N. V.; Soares, B.; Freire, C. S.; Silva, R.; Neto, C. P.; BarrosTimmons, A.; Ferreira, A. Bio-based Polyurethane Foams Toward Applications Beyond Thermal Insulation. Materials \& Design, 2015;
$76,77-85$.

25. Mosiewicki, M. A.; Dell'Arciprete, G. A.; Aranguren, M. I.; Marcovich, N. E. Polyurethane Foams Obtained from Castor Oil-Based Polyol and Filled with Wood Flour. Journal of Composite Materials, 2009; 43(25), 3057-3072.

26. Antunes, M.; Cano, Á.; Realinho, V.; Arencón, D.; Velasco, J. I. Compression Properties and Cellular Structure of Polyurethane Composite Foams Combining Nanoclay and Different Reinforcements. International Journal of Composite Materials, 2014; 4(5A), 27-34.

27. Patel, P. S.; Shepherd, D. E.; Hukins, D. W. Compressive Properties of Commercially Available Polyurethane Foams as Mechanical Models for Osteoporotic Human Cancellous Bone. BMC Musculoskeletal Disorders, 2008; 9(1), 137-144.

28. Avci, H.; Monticello, R.; Kotek, R. Preparation of Antibacterial PVA and PEO Nanofibers Containing Lawsonia Inermis (Henna) Leaf Extracts. Journal of Biomaterials Science, Polymer Edition, 2013; 24(16), 1815-1830.

29. Avci, H.; Kotek, R.; Yoon, J. Developing an Ecologically Friendly Isothermal Bath to Obtain a New Class High-Tenacity and High-Modulus Polypropylene Fibers. Journal of Materials Science, 2013; 48(22), 7791-7804

30. Keene, B.; Bourham, M.; Viswanath, V.; Avci, H.; Kotek, R. Characterization of degradation of polypropylene nonwovens irradiated by $\gamma$-ray. Journal of Applied Polymer Science, 2014; 131(4), 39917 (110).

31. Avci, H.; Ghorbanpoor, H.; Topcu, I.B.; Nurbas, M. Investigation and Recycling of Paint Sludge with Cement and Lime for Producing Lightweight Construction Mortar. Journal of Environmental Chemical Engineering, 2017; 5(1), 861-869. 